\title{
Bilateral ptosis as a presenting feature of primary hypertrophic osteoarthropathy (pachydermoperiostosis): a case report
}

\author{
S. El Aoud, F. Frikha, M. Snoussi, R. Ben Salah, Z. Bahloul \\ Department of Internal Medicine, Hedi Chaker Hospital, Sfax, Tunisia
}

\begin{abstract}
SUMMARY
Pachydermoperiostosis is a rare hereditary disorder, which affects both bones and skin. It is characterized by a combination of dermatologic changes (pachydermia or thickening of the skin) and rheumatologic manifestations (periostosis and finger clubbing). Eyelid ptosis which is caused by thickened eyelids (blepharoptosis) is a less common symptom. We report the case of a patient with a complete form of pachydermoperiostosis with bilateral ptosis as presenting feature.
\end{abstract}

Key words: Idiopathic hypertrophic osteoarthropathy, Periostosis, Ptosis, Arthritis.

Reumatismo, 2014; 66 (3): 249-253

\section{INTRODUCTION}

Dachydermoperiostosis (PDP) is a rare disease accounting for only $3 \%$ to $5 \%$ of all cases of hypertrophic osteoarthropathy $(\mathrm{HOA})(1,2)$.

It is a rare genetic disorder with autosomal dominant transmission. It occurs predominantly in men and has been reported in many ethnic groups. It is a clinical syndrome characterized by pachydermia, and periostosis which involves the distal parts of the extremities with a variety of clinical manifestations including clubbing of fingers and toes, a column-like enlargement of lower limbs, swelling or pain of large joints, hyperhidrosis of palms and soles, cutis verticis gyrata and hypertrophic gastritis. Patients may have one or more of these manifestations.

The common symptoms which make them consult a healthcare provider are joint manifestations and skin changes, which in general are the clues that lead to diagnose this rare, but easily recognizable clinical entity. Ptosis is a less common symptom. We report a case of complete pachydermoperiostosis we have treated in our department of internal medicine with ptosis as a presenting complaint.

\section{CASE REPORT}

A 20-year-old North African Tunisian male, whose parents are second-degree cousins, was admitted to our internal medicine department for puffiness and drooping of eyelids, which had been lasting for five months. He suffered from pain in knee and ankle joints with associated swelling, for three years. He was earlier seen by some generalists, who treated him with a highdose regimen of prednisone without improvement.

The physical examination revealed drooping of both eyelids, more pronounced in the left eye, with a narrowed palpebral fissure (Fig. 1). The skin of both eyelids was thick-

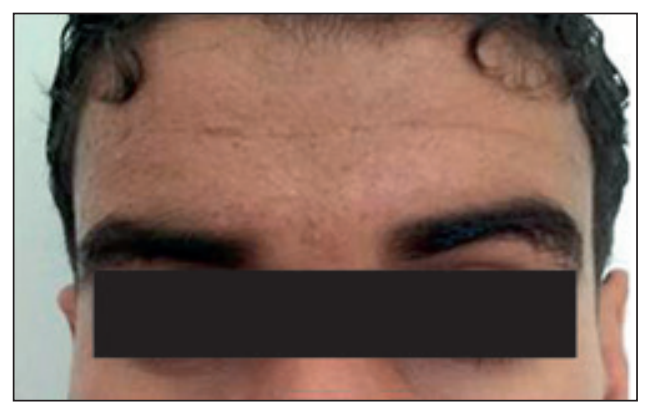

Figure 1 - Drooping of both eyelids and bilateral ptosis more marked in the left eye.
Corresponding author: Faten Frikha Department of Internal Medicine Hedi Chaker Hospital 3029 Sfax, Tunisia E-mail: fetenfrikha@yahoo.fr 


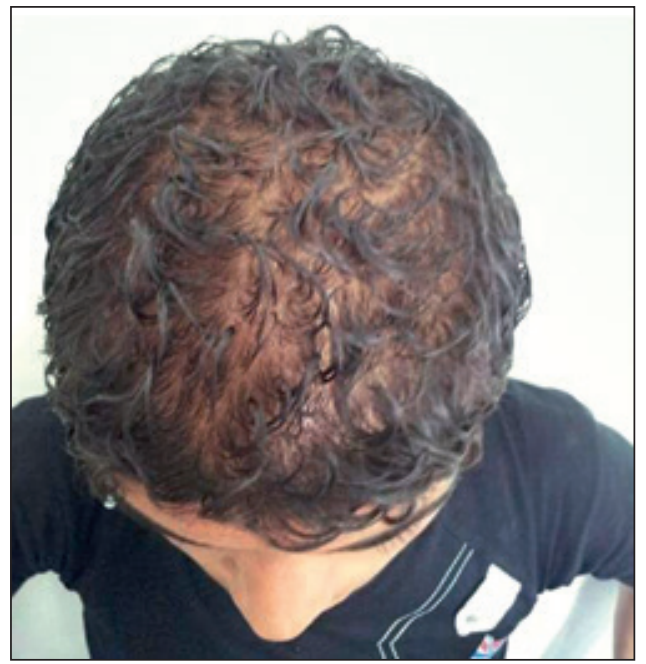

Figure 2 - Cutis verticis gyrata.

ened and non-pinchable. He had greasy and coarse skin with deep furrowed forehead skin, a seborrheic dermatitis and multiple folliculitis in the face. The scalp skin was folded with the appearance of a peculiar cutis verticis gyrate (Fig. 2). The patient showed pandigital clubbing and bulbous deformity of all digits of hand and feet (Fig. 3). In addition, he had hyperhydrosis of both palms and soles. Cutaneous examination over the rest of his body including mucosae was normal. There was joint effusion with a moderate restriction of motion in both knees. Joint fluid obtained by aspiration showed mechanical properties. The examination of cardiovascular system, respiratory system and abdomen revealed no significant abnormalities.

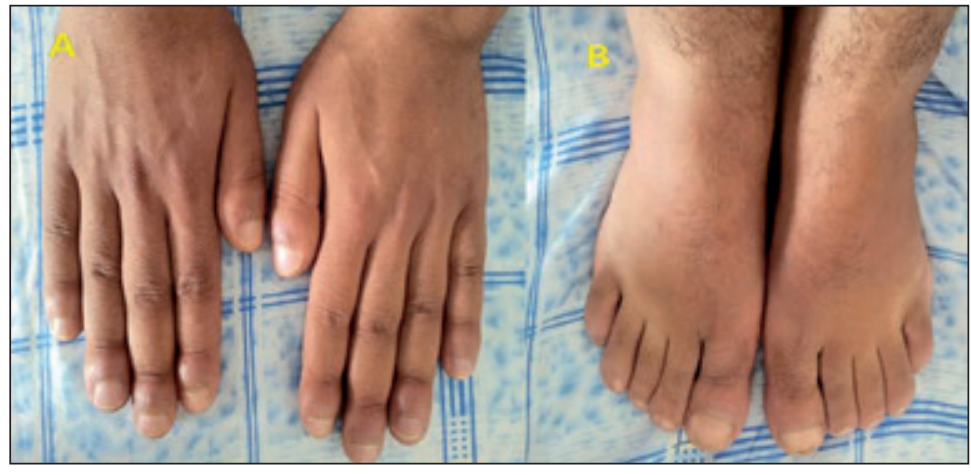

Figure 3 - Clubbing of fingers $(A)$ and toes (B).
Laboratory tests reported a white blood cell count of 10,540 cells $/ \mathrm{mL}$ with $50 \%$ neutrophils, a hemoglobin value of $13 \mathrm{~g} / \mathrm{dL}$, and a platelet count of 332,000 cells $/ \mathrm{mL}$. The erythrocyte sedimentation rate (ESR) was over $12 \mathrm{~mm} / \mathrm{h}$ and the C-reactive protein (CRP) was $47 \mathrm{mg} / \mathrm{L}$. Urea was $4 \mathrm{mg} /$ $\mathrm{dL}$ and creatinine was $47 \mu \mathrm{mol} / \mathrm{L}$. Serum calcium, phosphate, alkaline phosphatase, and liver function tests were normal. The rheumatoid factor and antinuclear antibodies (ANA) were negative. The growth hormone assay and thyroid profile were normal. Venereal disease research laboratory (VDRL) test for syphilis was negative. $\mathrm{X}$-rays of hands (Fig. 4) and femurs showed a sub-periosteal new bone formation and cortical thickening without narrowing of the medullary cavity. The chest $\mathrm{x}$-ray was normal. The skull $\mathrm{x}$-åray showed a normal pituitary fossa. The bone scintigraphy showed an exaggerated and symmetrical setting of the radiotracer throughout the lower end of all long bones especially the femurs, radius and tibia (Fig. 5).

The constellation of a thickened skin, a periosteal reaction in the long bones, clubbing and ptosis pointed to a clinical diagnosis of hypertrophic osteoarthropathy.

Based on the clinico-radiological correlation and after ruling out other secondary causes, the diagnosis of pachydermoperiostosis or primary HOA was made. Another feature of PDP, thickened eyelids with

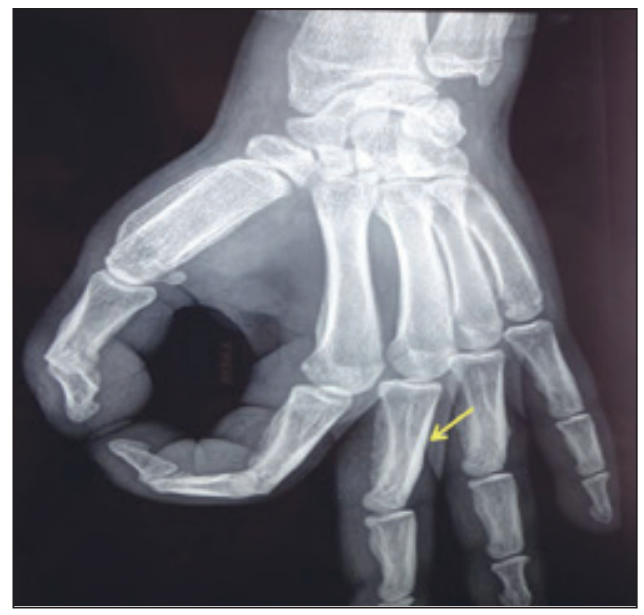

Figure 4 - X-ray of the right hand showing cortical thickening and periostosis. 


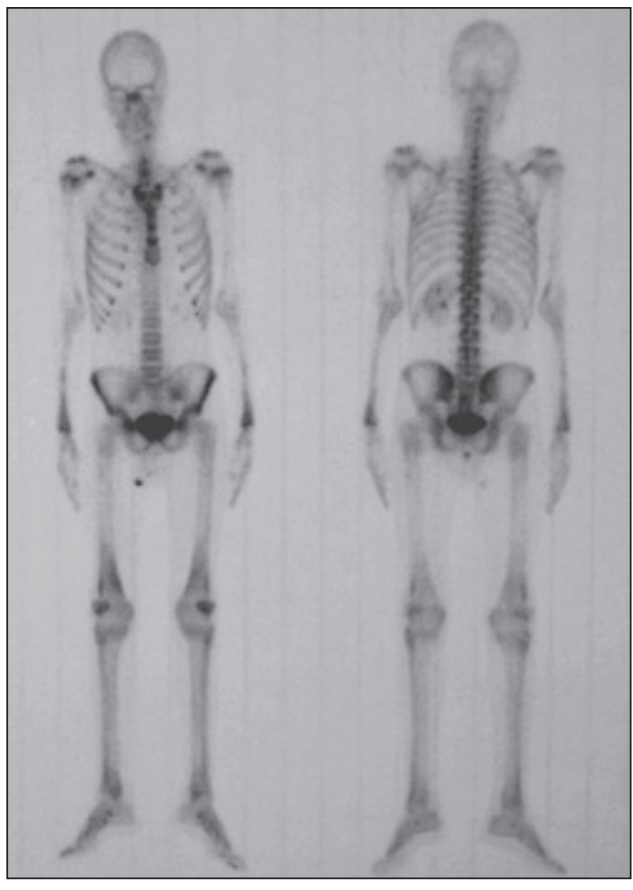

Figure 5 - Whole body bone scan: excessive and symmetrical setting of the radiotracer throughout the lower end of all long bones especially the femurs, radius and tibia.

ensuing mechanical ptosis, was a presenting complaint in our patient. He was treated symptomatically for the rheumatologic complaints with colchicine (1 mg per day) associated with oral paracetamol with a good response. He refused a surgical referral for ptosis.

\section{DISCUSSION}

PDP or primary hypertrophic osteoarthropathy (PHO) was first described by Nikolaus Friedreich in 1868. In 1935, Albert Touraine, Gabriel Solente and Laurent Gole identified it as a syndrome which was different from acromegaly and secondary hypertrophic pulmonary osteoarthropathy (3). The exact incidence is not known, but estimated prevalence is approximately $0.16 \%$ (4). Men are typically more affected than women with a ratio of 9:1 $(5,6)$. PDP is inherited in an autosomal dominant pattern with mainly variable expression and incomplete penetrance (7).
The pathogenesis of pachydermoperiostosisis is unclear. A larger prevalence of HLA B12 was reported in one study (8). It has been suggested that the central role in the pathogenesis of PHO is the increased levels of systemic or local prostaglandin E2 (PGE2), due to the failure of its degradation (9).

Three forms of PDP have been described: complete (pachydermia with periostosis and clubbing), incomplete (with evidence of bone abnormalities but lacking pachydermia) and mild (pachydermia with minimal or absent periostitis) (10). Because of the rarity and the variety of its clinical presentations, the diagnosis of PDP always requires a great deal of caution. It must be based on the presence of at least two of the four criteria set by Borochowitz, which are a history of familial transmission; pachyderma; digital clubbing; and skeletal manifestations, such as pain or radiographic signs of periostitis (11).

Our patient had the complete form of PDP revealed by ptosis which is a less common manifestation of this disease. There are only a few reported cases in the literature (12-20).

Ocular features in pachydermoperiostosis are mainly related to ptosis and chronic tarsitis. Ptosis is caused by a thickening of both eyelids. It has been correctly termed blepharoptosis to differentiate it from ptosis from neurologic causes. Sebaceous gland hyperplasia and dermal mucin deposition contribute to eyelid thickening and the development of ptosis (12). In general ptosis is not as severe as in our case. Other ocular co-morbidities reported in the literature are corneal leucoma, presenile macular dystrophy and cataract formation (13). Rheumatologic signs include joint effusion ( $41 \%$ of cases), often affecting the knees, with excess synovial joint fluid. Polyarthritis can occur in $20 \%$ to $40 \%$ of cases and is often symmetrical (21). This is due to cytokine-mediated tissue remodeling, endothelial cell activation and increased vascular stimulation leading to chronic hypertrophic synovitis (22). Joint fluid obtained by aspiration exhibits mechanical properties, as illustrated in our case-report. The 
characteristic radiologic features are cortical thickening and long bone periostitis, which is bilateral and symmetric. Periosteal reaction is irregular and often involves epiphysis (23).

The main differential diagnosis is secondary hypertrophic osteoarthropathy. Its etiologies include a host of cardiovascular, pleuropulmonary, gastrointestinal and hepatobiliary conditions, which should be ruled out before a diagnosis of PHO is confirmed. Thyroid acropachy and syphilitic periostosis should also be considered.

At present, there is no specific treatment for this disease. Non-steroidal anti-inflammatory drugs and corticosteroids are used in symptomatic patients to alleviate polyarthritis like in our case. Pamidronate, tamoxifen, octreotide and colchicine have been reported to be effective therapies in refractory cases (10). Plastic surgery is indicated for esthetic reasons to change the appearance of the facial and the scalp. Bilateral blepharoplasty, tarsal wedge resections and excisions of skin furrows can be helpful in some cases. Our patient was managed with colchicine and simply oral paracetamol for arthralgia with a good response at periodical follow-up.

\section{CONCLUSIONS}

Owing to the extreme rarity and varied presentation, the diagnosis of PCP requires a great deal of caution. Our patient had a complete form of pachydermoperiostosis with bilateral psosis as presenting feature. Conservative management is sufficient in most cases. Detailed investigation and early diagnosis may help in preventing disabilities later in life.

\section{Consent}

Written informed consent was obtained from the patient for the publication of this case report and any accompanying images.

Conflict of interest: the authors have no conflict of interest.

Contributions: all authors contributed to write this manuscript.

\section{REFERENCES}

1. Younes M, Touzi M, Béjia I, Zrour-Hassen S, Amara N, Ben Hammouda M, et al. Primary hypertrophic osteoarthropathy with bilateral destructive hip arthritis. Joint Bone Spine 2006; 73: 477-9.

2. Kumar S, Sidhu S, Mahajan BB. Tourainesoulente-golé syndrome: a rare case report and review of the literature. Ann Dermatol. 2013; 25: $352-5$

3. Touraine A, Solente G, Gole L. Un syndrome osteo-dermapathique:la pachydermie plicaturee avec pachyperiostse des extremites. Presse Med. 1935; 43: 1820-4.

4. Jajic I, Jajic Z. Prevalence of primary hypertrophic osteoar thropathy in selected population. Clin Ex Rheum. 1992; 10: 73.

5. Oikarinen A, Palatsi R, Kylmäniemi M, KeskiOja J, Risteli J, Kallioinen M. Pachydermoperiostosis: analysis of the connective tissue abnormality in one family. J Am Acad Dermatol. 1994 ; 31: 944-53.

6. Resnick D. Enostosis, hyperostosis, and periostitis. In: Resnick D, Kransdorf MJ, eds. Bone and joint imaging. 3rd ed. Philadelphia, PA: Elsevier Saunders; 2005; 1433-5.

7. Rimoin DL. Pachydermoperiostosis (Idiopathic Clubbing and Periostosis). Genetic and physiologic considerations. N Engl J Med. 1965; 272: 923-31.

8. Jajic I, Jajic Z, Ozie-Bebek M. HLA antigens and primary hypertrophic osteoarthropathy. Clin Exp Rheum. 1992; 10: 74.

9. Zhang Z, He JW, Fu WZ, Zhang CQ, Zhang ZL. Two novel mutations in the SLCO2A1 gene in a Chinese patient with primary hypertrophic osteoarthropathy. Gene 2014; 534: 421-3.

10. Shin KC, Chung WJ, Lee KY, Shin MS, Kim $\mathrm{SH}$, Jo YJ, et al. Pachydermoperiostosis accompanied by heart failure. J Cardiovasc Ultrasound. 2009; 17: 135-7.

11. Ka MM, Ka EF, Dia D, Sy MH, Diallo S, Mbengue M, Dia M, Diop TM. An incomplete form of pachydermoperiostosis. Diagnosis of clubbing. J Intern Med. 2002; 23: 728-32.

12. Offret H, Venencie PY, Fain J, Quillard J, Badarani N. [Involvement of the connective tissue of the eyelids in pachydermoperiostosis]. J Fr Ophthalmol. 1996; 19: 64-8 [Article in French].

13. Kirkpatrick JNP, McKee PH, Spalton DJ. Ptosis caused by pachydermoperiostosis. $\mathrm{Br} \mathrm{J}$ Ophthalmol. 1991; 75: 442-6.

14. Ben Rayana-Chekir N, Khochtali S, Yakoubi S, Touzani F, Ben Hadj Hamida F. Ptosis associated with pachydermoperiostosis. J Fr Ophtalmol. 2013; 36: e133-6.

15. Mahesh M, Murthy KV. Bilateral ptosis due to a rare cause pachydermoperiostosis. J Clin Diagn Res. 2013; 7: 1450-2. 
16. Arinci A, Tümerdem B, Karan MA, Erten N, Büyükbabani N. Ptosis caused by pachydermoperiotosis. Ann Plast Surg. 2002; 49: 3235.

17. Alves AP, Holanda Filha JG, Jerônimo FT. Eyelid ptosis associated with pachydermoperiostosis: case report. Arq Bras Oftalmol. 2005; 68: 401-4.

18. Davidson SI, Smith JL. Pachydermoperiostosis: a rare cause of ptosis. Trans Ophthalmol Soc UK. 1970; 90: 539-50.

19. Berdia J, Tsai FF, Liang J, Shinder R. Pachydermoperiostosis: a rare cause of marked blepharoptosis and floppy eyelid syndrome. Orbit. 2013; 32: 266-9.

20. Ding J, Li B, Chen T, Hao L, Li D. Eyelid thickening and ptosis associated with pachydermoperiostosis: a case report and review of literature. Aesthetic Plast Surg. 2013; 37: 464-7.

21. Kabi F, Mkinsi O, Janani S, Raissouni N. Pachydermoperiostosis. A case report. J Intern Med. 2006; 27: 710-2.

22. Warwas S, Specker C, Jäger M, Landgraeber S. Arthroscopic synovectomy and radiosynoviorthesis: a treatment option for recurrent arthritis symptoms in patients with pachydermoperiostosis. Reumatismo 2013; 65: 82-5.

23. Baert AL. Hypertrophic osteoarthropathy. In: Bauer JS, ed. Encyclopedia of diagnostic imaging. 1st ed. Berlin, New York, Hiedelberg: Springer; 2008; 929-931. 